\title{
ASSOCIAÇÕES DE HERBICIDAS NA DESSECAÇÃO PRÉ-SEMEADURA DE SOJA
}

\author{
HERBICIDES ASSOCIATIONS FOR BURNDOWN PRIOR SOYBEAN SOWING
}

Andressa Serafim de Quadros ${ }^{\mathrm{a}}$, Luísa Bandeira, Natália Kasper ${ }^{\mathrm{a}}$, Pedro Luís da Costa Aguiar Alves ${ }^{\mathrm{b}}$, Lessandro De Conti ${ }^{\mathrm{a}}$, Paulo Roberto Fidelis Giancotti ${ }^{\mathrm{a} *}$

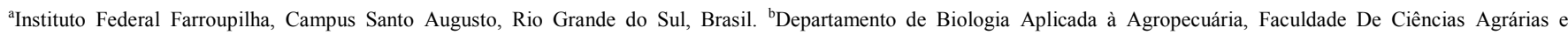
Veterinárias de Jaboticabal, Universidade Estadual Paulista "Júlio de Mesquita Filho", São Paulo, Brasil.

*Autor correspondente: paulogiancotti@gmail.com.

\section{INFORMAÇÕES DO ARTIGO}

\section{Histórico do artigo:}

Recebido: 19 Fevereiro 2020.

Aceito: 24 Setembro 2020.

Publicado: 02 Outubro 2020.

\section{Palavras-chave/Keywords:}

Glycine max L./ Glycine max L.

Glifosato/ Glyphosate.

Setoxidim/ Sethoxydim.

2,4-D/2,4-D.

Plantas daninhas/ Weeds.

Financiamento:

Financiamento do Instituto Federal Farroupilha (IFFar).

Direito Autoral: Este é um artigo de acesso aberto distribuído sob os termos da Licença Creative Commons, que permite uso, distribuição e reprodução irrestritos em qualquer meio, desde que $\mathrm{o}$ autor $\mathrm{e}$ a fonte originais sejam creditados.

\section{Citação deste artigo:}

QUADROS, A. S.; BANDEIRA, L.; KASPER, N.; ALVES, P. L. C. A.; CONTI, L.; GIANCOTTI, P. R. F. Associações de herbicidas na dessecação pré-semeadura de soja. Revista Brasileira de Herbicidas, v. 19, n. 2. 2020.

\begin{abstract}
RESUMO
$\mathrm{Na}$ cultura da soja transgênica, plantas daninhas resistentes ao glifosato, como buva (Conyza spp.) e azevém (Lolium multiflorum L.), apresentam difícil controle, tornando-se necessário associar esse herbicida a outros com diferentes mecanismos de ação. O objetivo do estudo foi avaliar a influência da associação de herbicidas para o controle de plantas daninhas resistentes ao glifosato na dessecação pré-semeadura na cultura da soja e o desenvolvimento e produtividade da cultura. O experimento foi implantado na safra 2018/2019, em delineamento experimental em blocos casualizados, com oito repetições, numa área agrícola que passou o inverno em pousio. Os tratamentos experimentais foram compostos por três associações de herbicidas aplicadas aos 40 dias antecedendo a semeadura da soja TMG 7062 IPRO, sendo eles: glifosato + setoxidim, glifosato + 2,4-D + setoxidim e glifosato + 2,4-D. As associações do glifosato com os herbicidas 2,4-D e setoxidim na dessecação présemeadura da soja proporcionaram maior controle de plantas daninhas de folha larga e estreita, respectivamente. Não foram encontrados efeitos de sinergismo ou antagonismo nas associações dos herbicidas, apenas efeito de adição, melhorando o espectro de controle. Os tratamentos de dessecação pré-semeadura não proporcionaram efeito sobre o índice de clorofila Falker, tampouco na produtividade e componentes de rendimento de grãos da cultura.
\end{abstract}

\begin{abstract}
In the soybean crop, weed resistant to glyphosate, such as horseweed and ryegrass, are difficult to control, making it necessary to associate other herbicides with different mechanisms of action. The objective of the study was to evaluate the influence of the association of herbicides to control glyphosate resistant weed in the soybean pre-planting desiccation and crop development and yield. The experiment was carried out in the 2018/2019 crop year, in an agricultural area that spent the winter fallow. The experiment used a randomized block design with eight replications. The experimental treatments consisted of three different combinations of herbicides applied in pre-planting of the soybean crop, 40 days before sowing the cultivar TMG 7062 IPRO: glyphosate + sethoxydim, glyphosate $+2,4-\mathrm{D}+$ sethoxydim and glyphosate $+2,4-\mathrm{D}$. The associations of glyphosate with the herbicides 2,4-D and setoxidim in the pre-sowing desiccation of soybean provided greater control of broad and narrow leaf weeds, respectively. No synergism or antagonism effects were found in the herbicide associations, only addition effect improving the control. The different pre-planting desiccation treatments provided no effect on the Falker chlorophyll index, nor on the grain yield and its components.
\end{abstract}


A. S. QUADROS et al.

\section{Introdução}

Na cultura da soja (Glycine max L.) geneticamente modificada para tolerância ao glifosato, plantas daninhas resistentes a esse herbicida apresentam dificuldade de controle químico e, por isso, faz-se necessário utilizar outros herbicidas com diferentes mecanismos de ação. O Rio Grande do Sul é o terceiro maior produtor de soja no Brasil, onde foram cultivados na safra 2017/2018 cerca de 5,7 milhões de hectares com a cultura (EMBRAPA, 2018). O uso repetido de um herbicida ou de herbicidas que controlam as plantas daninhas utilizando o mesmo mecanismo de ação herbicida permite que algumas plantas sobrevivam e se reproduzam (BHATTI et al., 2013). Assim, o número de plantas resistentes na população aumenta até que o herbicida reduz sua capacidade de controle efetivo (BARROS; CALADO, 2020).

O glifosato é um herbicida sistêmico que inibe a enzima EPSPs (5-enolpiruvoil-shikimato-3-fosfato sintetase), com uma grande gama de recomendações e eficácia e tem sustentado o controle de um amplo espectro de controle de plantas daninhas (ZAVARIZ et al., 2020). Entretanto, algumas espécies têm sido reportadas pelo desenvolvimento de resistência a esse herbicida, dentre elas a buva (Conyza spp.) e o azevém (Lolium multiflorum L.) (DALAZEN;KRUSE; MACHADO, 2015a).

Nesse cenário, a associação de herbicidas em mistura de tanque é uma prática frequente e conveniente operacionalmente. No entanto, as moléculas dos diferentes herbicidas podem sofrer interações químicas após a mistura, alterando sua absorção, translocação e metabolização em plantas alvo alteradas, dado o efeito antagônico entre herbicidas (COSTA et al., 2019). A possibilidade ou não da ocorrência de antagonismo entre herbicidas associados depende das características do herbicida, da composição da calda de aplicação e do alvo.

O setoxidim é uma molécula pertencente ao grupo químico da oximaciclo hexanodionas, com mecanismo de ação de inibição da ACCase (acetil-CoA carboxilase), sendo um herbicida eficiente no controle de plantas daninhas gramíneas, como o azevém, e seletivos para a soja (RODRIGUES; ALMEIDA, 2011). O 2,4-D, uma auxina sintética, é um herbicida de ótima translocação via aposimplasto e de grande eficácia para o controle de espécies de folhas largas, apresentando efeito inclusive para a buva resistente ao glifosato quando em pós-emergência inicial (RODRIGUES; ALMEIDA, 2011).

Em virtude desse relato, o estudo teve como objetivo avaliar a influência da associação de herbicidas glifosato, setoxidim e 2,4-D no tanque de pulverização para controle de buva e azevém na dessecação pré-semeadura de soja e o possível impacto no desenvolvimento e produtividade da cultura.

\section{Material e métodos}

O experimento foi conduzido na área experimental do Instituto Federal Farroupilha - campus Santo Augusto, na cidade de Santo Augusto - RS (27 $51^{\prime} 13^{\prime \prime}$ S e $53^{\circ} 47^{\prime}$
32" W, 494 m). O clima segundo Köppen (1948), é classificado como do tipo $\mathrm{Cfa}$, com temperatura média anual de $19,1^{\circ} \mathrm{C}$ e precipitação média anual de $1833 \mathrm{~mm}$. O solo da área de estudo é classificado no Sistema Brasileiro de Classificação de Solos como Latossolo Vermelho Distroférico (SANTOS et al., 2018). A área experimental esteve em pousio no inverno de 2018, inclusive com histórico de presença de azevém (Lolium multiflorum L.) e buva (Conyza spp.).

Os tratamentos experimentais foram dispostos em blocos casualizados, com oito repetições. Cada parcela foi composta por cinco linhas da soja, espaçadas entre si em $0,5 \mathrm{~m}$, com $6,5 \mathrm{~m}$ de comprimento cada, totalizando $16,25 \mathrm{~m}^{2}$. Para as avaliações, foram utilizadas as três linhas centrais de cada parcela, correspondendo a $9,75 \mathrm{~m}^{2}$.

Os tratamentos foram compostos pela aplicação de três associações de herbicidas em dessecação aos 40 dias antecedendo a semeadura da soja: T1. glifosato $720 \mathrm{~g} \mathrm{ha}^{-1}$ e.a. (Glifosato Nortox SL, 360 g i.a. L ${ }^{-1}$, SL, Nortox) + setoxidim $230 \mathrm{~g} \mathrm{ha}^{-1}$ i.a. (Poast, $184 \mathrm{~g}$ i.a. $\mathrm{L}^{-1}$, DC, Basf); T2. glifosato $720 \mathrm{~g} \mathrm{ha}^{-1}$ e.a. (Glifosato Nortox SL, 360 g i.a. $L^{-1}$, SL, Nortox) + 2,4-D 1.340 g ha ${ }^{-1}$ e.a. (U46 BR, 670 g e. a. L ${ }^{-1}$, SL, Nufarm) + setoxidim $230 \mathrm{~g} \mathrm{ha}^{-1}$ i. a. (Poast, $184 \mathrm{~g}$ i. a. L ${ }^{-1}, \mathrm{DC}$, Basf); T3. glifosato $720 \mathrm{~g} \mathrm{ha}^{-1}$ e. a. (Glifosato Nortox SL, $360 \mathrm{~g}$ i. a. $\mathrm{L}^{-1}$, SL, Nortox) + 2,4-D $1.340 \mathrm{~g} \mathrm{ha}^{-1}$ e. a. (U46 BR, 670 g e. a. $\mathrm{L}^{-1}$, SL, Nufarm).

Cinco dias antecedendo a semeadura da soja foi realizada uma aplicação de glifosato $720 \mathrm{~g} \mathrm{ha}^{-1}$ e. a. (Glifosato Nortox SL, 360 g i. a. $\mathrm{L}^{-1}$, SL, Nortox), em toda a área experimental, prática comum dos agricultores da região, a fim de controlar as plantas que sobreviveram por efeito guarda-chuva e as que emergirem após a primeira aplicação.

Para a aplicação dos tratamentos experimentais, utilizou-se um pulverizador costal pressurizado com $\mathrm{CO}_{2}$, equipado com barra de pulverização com quatro pontas tipo TTI 110.05 espaçadas a $0,5 \mathrm{~m}$ entre si. A velocidade de deslocamento e a pressão $(200 \mathrm{kPa})$ foram ajustadas para obter um volume de aplicação de $150 \mathrm{~L} \mathrm{ha}^{-1}$. No momento da aplicação foi registrada a velocidade do vento em $3 \mathrm{~km} \mathrm{~h}^{-1}$ e não houve precipitação após as aplicações dos tratamentos neste dia.

A semeadura do cultivar de soja 'TMG 7062 IPRO' foi realizada no dia 20 de novembro de 2018, depositandose 14 sementes por metro com espaçamento entre linhas de 0,5 m. A adubação foi realizada conforme a recomendação para os estados do Rio Grande do Sul e Santa Catarina (CQFS-RS/SC, 2016), utilizando os resultados da análise de solo e a expectativa de rendimento de $4.000 \mathrm{~kg} \mathrm{ha}^{-1}$ de grãos.

No dia da semeadura, as sementes foram tratadas com inseticida e fungicida recomendados para a cultura da soja (AGROFIT, 2019). Após a secagem dos produtos nas sementes, foi realizada a inoculação com bactérias Bradyrhizobium sp. Foi aplicado adubo formulado NPK em linha, de forma simultânea à operação de semeadura (CQFS -RS/SC, 2016). Os demais tratos culturais, como aplicação de inseticidas e fungicidas ao longo do ciclo da soja foram realizados conforme padrões regionais para a cultura 
(SEDIYAMA; SILVA; BORÉM, 2015).

O controle das plantas daninhas em pós-emergência da cultura foi realizado com duas aplicações de glifosato $720 \mathrm{~g} \mathrm{ha}^{-1}$ e.a. (Glifosato Nortox SL, $360 \mathrm{~g}$ i. a. $\mathrm{L}^{-1}$, SL, Nortox), sendo a primeira, 30 dias após a semeadura e a segunda, 60 dias.

No dia da aplicação dos tratamentos, foi feita uma amostragem das plantas daninhas presentes utilizando dois quadros amostrais vazados de $0,25 \mathrm{~m}^{2}$ locados aleatoriamente em cada parcela, sendo identificadas utilizando literatura especializada (LORENZI, 2006), coletadas separadamente e determinada a massa seca, após secagem em estufa com circulação forçada de ar a $65^{\circ} \mathrm{C}$ durante $72 \mathrm{~h}$. Essa avaliação de biomassa das plantas daninhas foi feita também aos 20,35 e 75 dias após a aplicação (DAA) dos tratamentos, a fim de se verificar o controle ou a reinfestação. Vale ressaltar que a avaliação de 35 DAA coincidiu com a segunda dessecação com herbicida glifosato, cinco dias antecedendo a semeadura de soja. Já a avaliação aos 75 DAA ocorreu 35 dias após a semeadura da cultura da soja.

No estádio de desenvolvimento R5.2 da cultura (maioria das vagens entre $10 \%$ e $25 \%$ da granação máxima), foi determinado o índice de clorofila Falker (ICF), por meio de um clorofilômetro ClorofiLog Falker, modelo CFL1030. Em seis plantas de cada repetição, foram realizadas leituras na terceira folha madura do terço superior da haste principal, que é a posição de coleta preconizada para diagnose nutricional foliar (CQFS-RS/SC, 2016).

No momento da colheita, aos 134 dias após a semeadura, foi determinada a altura das plantas (distância da superfície do solo até a ponta da última folha estendida), altura do primeiro nó (desde a superfície do solo), número de nós por planta. Também foram amostradas 5 plantas das linhas centrais ao acaso, em cada parcela, para determinação do número de vagens por planta e do número médio de grãos por vagem. Para determinação da produtividade de grãos, foi colhido $1 \mathrm{~m}$ na linha central e, posteriormente, realizada a trilha e separação manual dos grãos, sendo os dados transformados em $\mathrm{kg} \mathrm{ha}^{-1}$ a $13 \%$ de umidade. A massa de 1000 sementes foi determinada por meio da contagem de 8 repetições de 100 sementes e pesagem em balança analítica.

Os resultados obtidos foram submetidos à análise de variância (ANOVA) pelo software SISVAR, versão 4.0 (FERREIRA, 2011), e as médias comparadas pelo teste de Tukey $(p \leq 0,05)$. A apresentação da estatística em tabelas e gráficos foram elaborados no software Microsoft Excel 2013.

\section{Resultados e discussão}

Na Figura 1, as plantas daninhas estão agrupadas em espécies de folha larga e espécies de folha estreita. De 899 $\mathrm{kg}$ de biomassa de plantas daninhas ha ${ }^{-1}$ estimados, $95 \%$ foram de espécies de folha estreita, sendo destes $802 \mathrm{~kg} \mathrm{ha}^{-1}$ foram de azevém. Na Tabela 1 é listada todas as espécies de plantas daninhas encontradas durante as avaliações de biomassa.

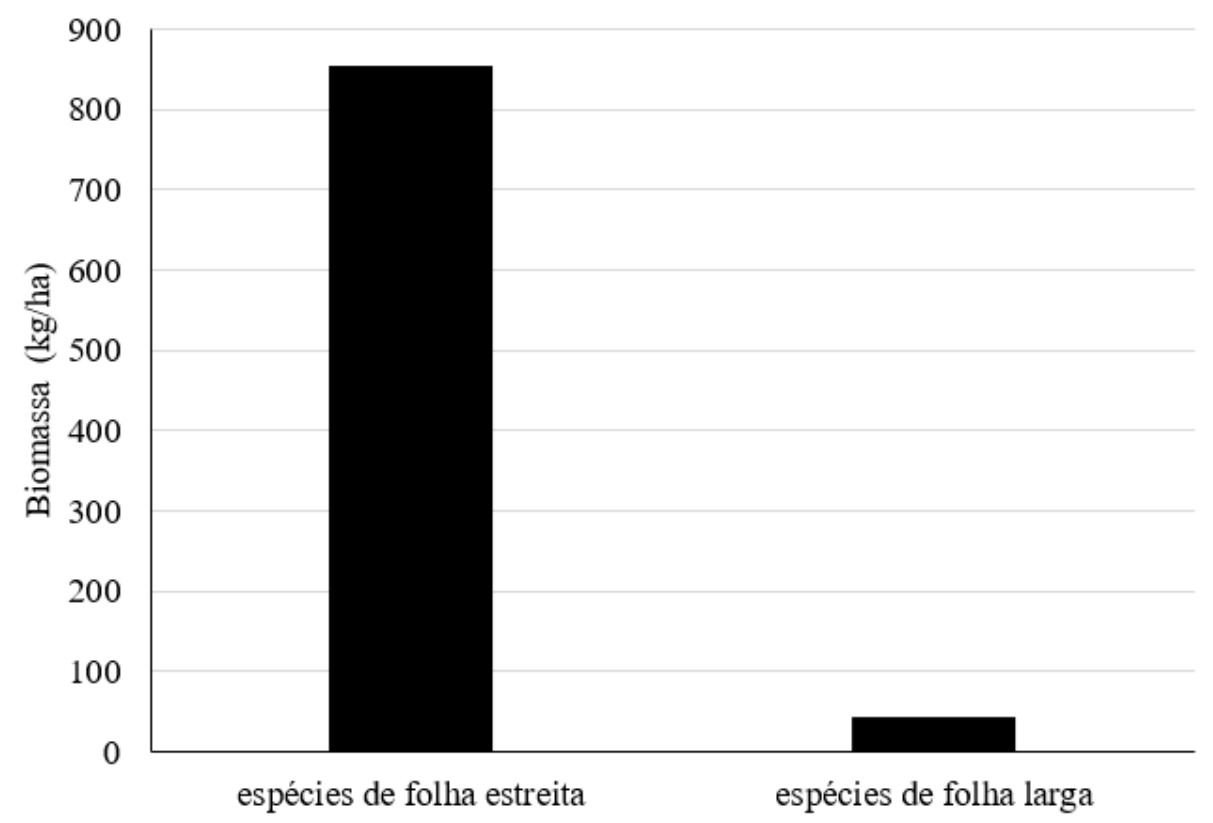

Figura 1. Biomassa de plantas daninhas na área experimental no dia da aplicação dos tratamentos de dessecação química pré-semeadura. 
A. S. QUADROS et al.

Tabela 1. Nomes científicos e famílias de plantas daninhas presentes durante as avaliações de biomassa.

\begin{tabular}{|c|c|c|c|c|}
\hline Tipo de folha & Família & Espécie & Nome comum & Massa seca $\left(\mathrm{kg} \mathrm{ha}^{-1}\right)$ no dia da aplicação dos tratamentos \\
\hline Estreita & Poaceae & Lolium multiflorum $\mathrm{L}$. & Azevém & 1603,800 \\
\hline Estreita & Poaceae & Andropogon bicornis $\mathrm{L}$. & Rabo de burro & 105,360 \\
\hline Estreita & Poaceae & Digitaria horizontalis Willd. & Capim milhã & $*$ \\
\hline Estreita & Poaceae & Cenchrus echinatus $\mathrm{L}$. & Capim carrapicho & $*$ \\
\hline Estreita & Poaceae & Chloris polydactyla (L.) Sw. & Capim-branco & * \\
\hline Larga & Asteraceae & Conyza spp. & Buva & 14,127 \\
\hline Larga & Apiaceae & Bowlesia incana Ruiz \& Pav. & Erva-salsa & 63,927 \\
\hline Larga & Brassicaceae & Raphanus Raphanistrum L. & Nabiça & 3,400 \\
\hline Larga & Commelinaceae & Commelia benghalensis $\mathrm{L}$. & Trapoeraba & 0,467 \\
\hline Larga & Euphorbiaceae & Euphorbia heterophylla L. & Leiteiro & 0,120 \\
\hline Larga & Asteraceae & Achyrocline satureioides (Lam.) DC. & Macela & 1,553 \\
\hline Larga & Asteraceae & Sonchus oleraceus $\mathrm{L}$. & Serralha & 5,180 \\
\hline Larga & Asteraceae & Bidens pilosa $\mathrm{L}$. & Picão-preto & $*$ \\
\hline
\end{tabular}

*Espécies de plantas daninhas não amostradas durante a avaliação da comunidade de plantas daninhas no dia da aplicação dos tratamentos de dessecação.

Comparando-se a biomassa de plantas daninhas de folha estreita antes da aplicação dos tratamentos e 20 dias após, observa-se uma redução de 855 para $106 \mathrm{~kg} \mathrm{ha}^{-1}$, ou seja, um controle de $88 \%$ da biomassa desse grupo de plantas, por meio da aplicação de glifosato + 2,4-D (Figuras
1 e 2). A adição do setoxidim (inibidor de ACCase), causou uma redução na biomassa para $22 \mathrm{~kg} \mathrm{ha}^{-1}(97 \%)$. Na associação dos três herbicidas (glifosato + setoxidim + 2,4-D), houve redução de $99 \%$ da biomassa, apresentando $12 \mathrm{~kg} \mathrm{ha}^{-1}$.

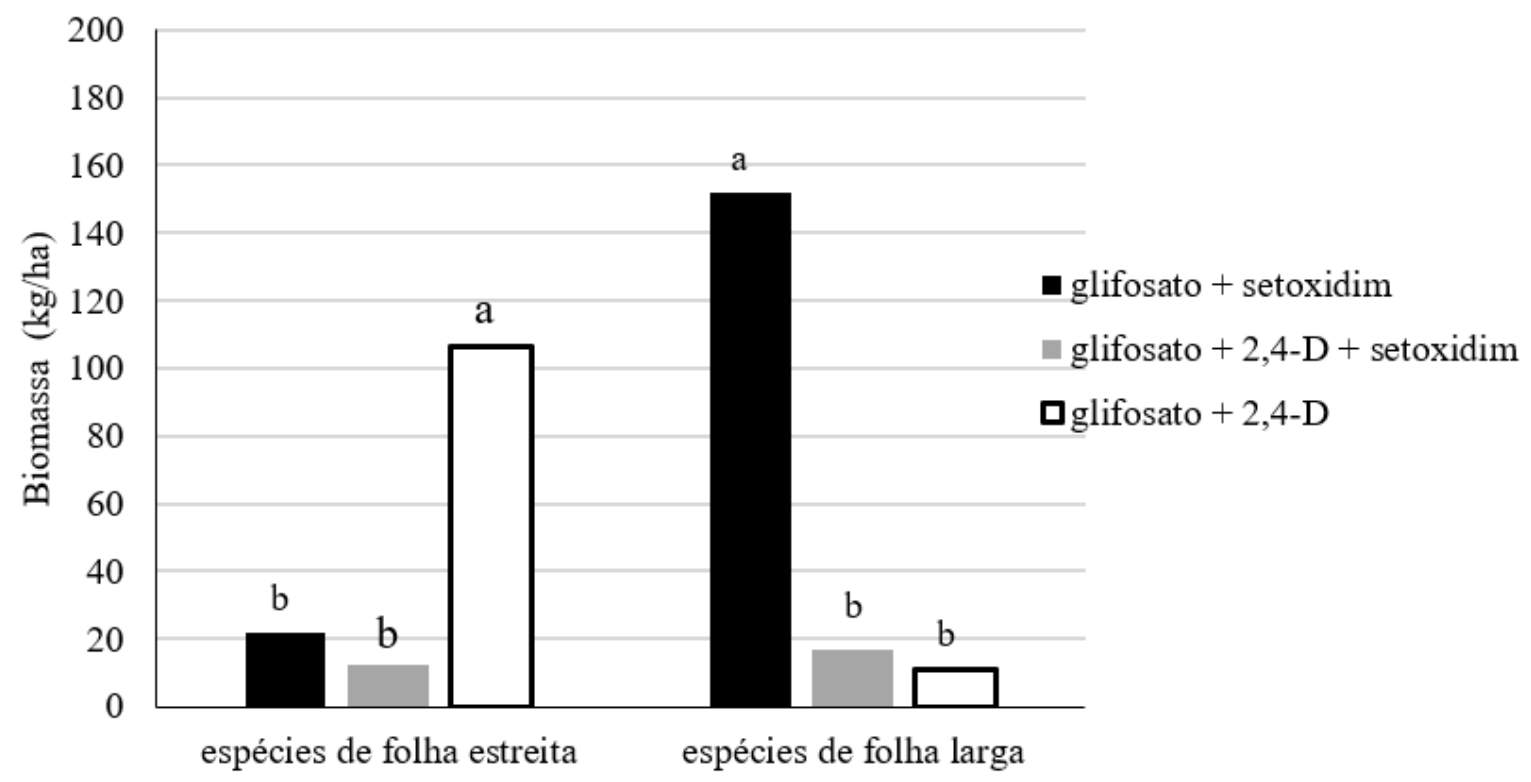

Figura 2. Biomassa de plantas daninhas, 20 dias após dessecação pré-semeadura da soja, utilizando diferentes associações herbicidas. Médias seguidas pela mesma letra dentro de cada grupo de plantas não diferem entre si pelo teste de Tukey a $5 \%$ de probabilidade de erro. CV espécies folha estreita $=29 \%$. CV espécies de folha larga $=45 \%$. 
As espécies de folha larga apresentaram um aumento de $44 \mathrm{~kg}$ para $152 \mathrm{~kg} \mathrm{ha}^{-1}$ na biomassa, 20 dias após a aplicação do glifosato sem o 2,4-D; ou seja, a produção de biomassa dessas plantas, em especial a buva, mais que triplicou (Figuras 1 e 2). A aplicação de glifosato + 2,4-D, reduziu a biomassa das plantas daninhas em $76 \%$, com $10 \mathrm{~kg} \mathrm{ha}^{-1}$. Esse percentual de controle foi estatisticamente semelhante ao da associação dos três diferentes ingredientes ativos (89\%).

Aos 35 dias após a aplicação dos tratamentos herbicidas, o padrão de comportamento se manteve semelhante ao dos 20 dias para as espécies de folha estreita. Houve uma redução da biomassa destas plantas daninhas nos tratamentos com glifosato + setoxidim $\left(10 \mathrm{~kg} \mathrm{ha}^{-1}\right) \mathrm{e}$ glifosato + 2,4-D $\left(20 \mathrm{~kg} \mathrm{ha}^{-1}\right)$ em comparação com o tratamento glifosato $+2,4-\mathrm{D}+\operatorname{setoxidim}\left(110 \mathrm{~kg} \mathrm{ha}^{-1}\right)$ (Figura 3). Houve aumento expressivo da biomassa das plantas daninhas de folha larga dos 20 dias após a aplicação dos tratamentos com a biomassa aos 35 dias (Figuras 2 e 3 ). Aos 20 dias após a aplicação dos tratamentos com 2,4-D não chegavam a $20 \mathrm{~kg} \mathrm{ha}^{-1}$, já, após 15 dias, apresentaram biomassa de aproximadamente $80 \mathrm{~kg} \mathrm{ha}^{-1}$.

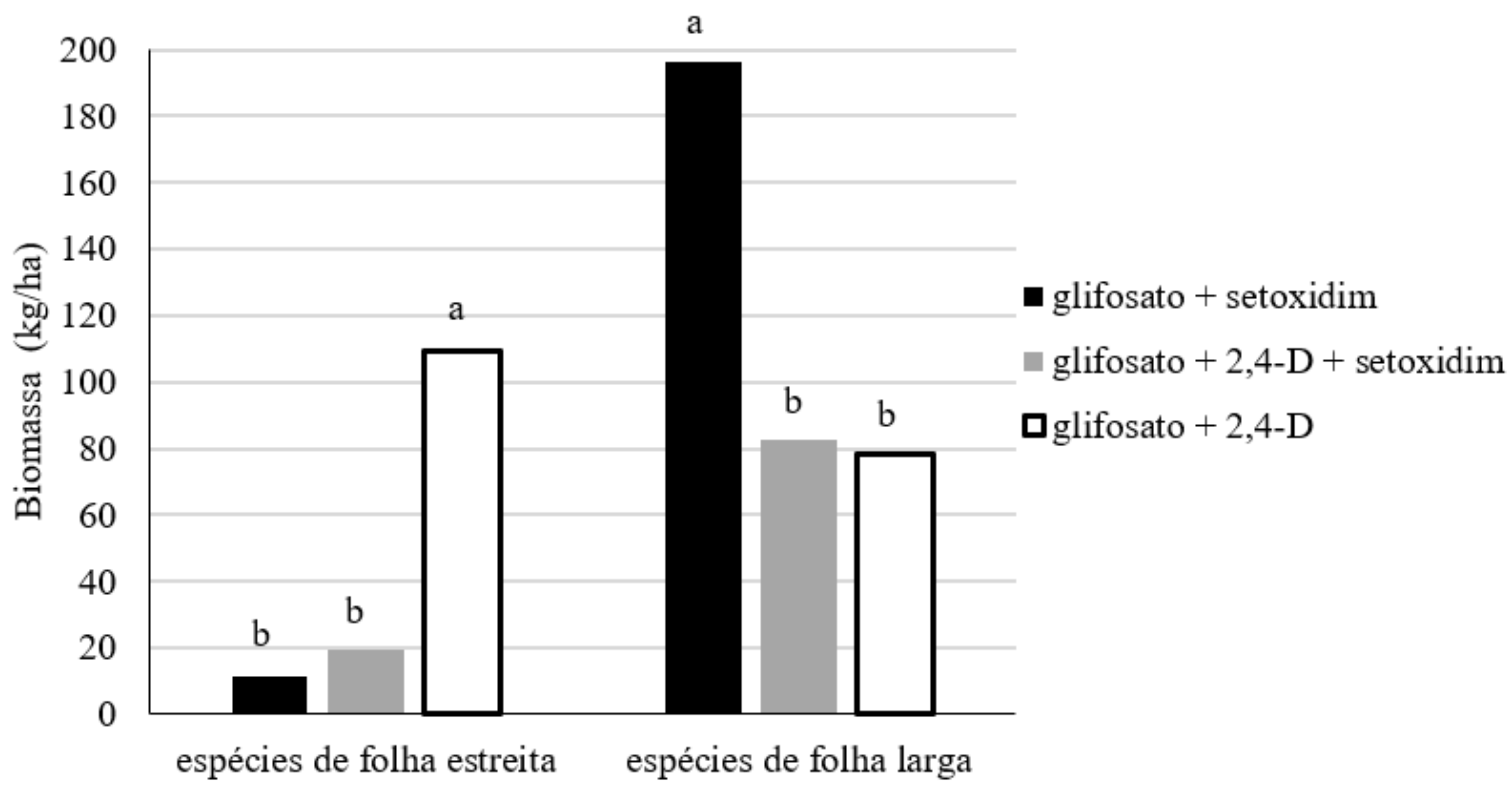

Figura 3. Biomassa de plantas daninhas aos 35 dias após dessecação pré-semeadura da soja (dia da segunda dessecação com glifosato), utilizando diferentes associações herbicidas. Médias seguidas pela mesma letra dentro de cada grupo de plantas não diferem entre si pelo teste de Tukey a 5\% de probabilidade de erro. CV espécies folha estreita $=29 \%$. CV espécies de folha larga $=12 \%$.

Aos 75 dias após a dessecação pré-semeadura, houve redução da biomassa das plantas daninhas, em relação ao período de avaliação anterior (35 dias após a dessecação), seja espécies de folha larga como as de folha estreita (Figura 4). Lembrando que, aos 35 dias após a aplicação dos tratamentos foi aplicada a segunda dessecação, com glifosato em toda a área, cinco dias antes da semeadura da cultura.

O Índice de Clorofila Falker (ICF) não diferiu entre os tratamentos herbicidas para dessecação da soja cultivar 'TMG 7062 IPRO', com uma média de 55 (Tabela 2).

A média de altura do primeiro nó visível e a altura das plantas de soja foram maiores $(\mathrm{p}>0,05)$ no tratamento com glifosato + 2,4-D do que nos outros tratamentos. Outro parâmetro de desenvolvimento da planta, número de nós, não variou significativamente entre os tratamentos de dessecação pré-semeadura (Tabela 3 ).

Os componentes de rendimento da cultura, número de vagens por planta, número de grãos por planta e peso de mil grãos, não variaram com os diferentes tratamentos, apresentando valores médios de respectivamente 49,112 e $23 \mathrm{~g}$ (Tabela 3). A produtividade de grãos de soja também não sofreu diferença significativa com os diferentes tratamentos herbicidas na dessecação pré-semeadura. Tal parâmetro da cultura apresentou uma média de $4771 \mathrm{~kg} \mathrm{ha}^{-1}$ o que representa 79,5 sacas ha ${ }^{-1}$.

Populações de azevém resistentes ao herbicida glifosato são frequentes em todas as regiões do Rio Grande do Sul, sendo reportadas desde 2003 (HEAP, 2014). No presente experimento, houve uma redução das plantas daninhas de folha estreita em $88 \%$, após 20 dias, com a aplicação de glifosato sem o graminicida (Figura 2). Uma vez que o controle das plantas daninhas acima de $80 \%$ pode ser considerado satisfatório (AMIM et al., 2014), é possível inferir que a maioria das plantas de azevém presentes na área não eram resistentes ao glifosato. Entretanto, a associação com herbicida setoxidim, demonstrou um resultado significativamente superior, ao controlar também a população de biótipos de azevém presentes na área. 
A. S. QUADROS et al.

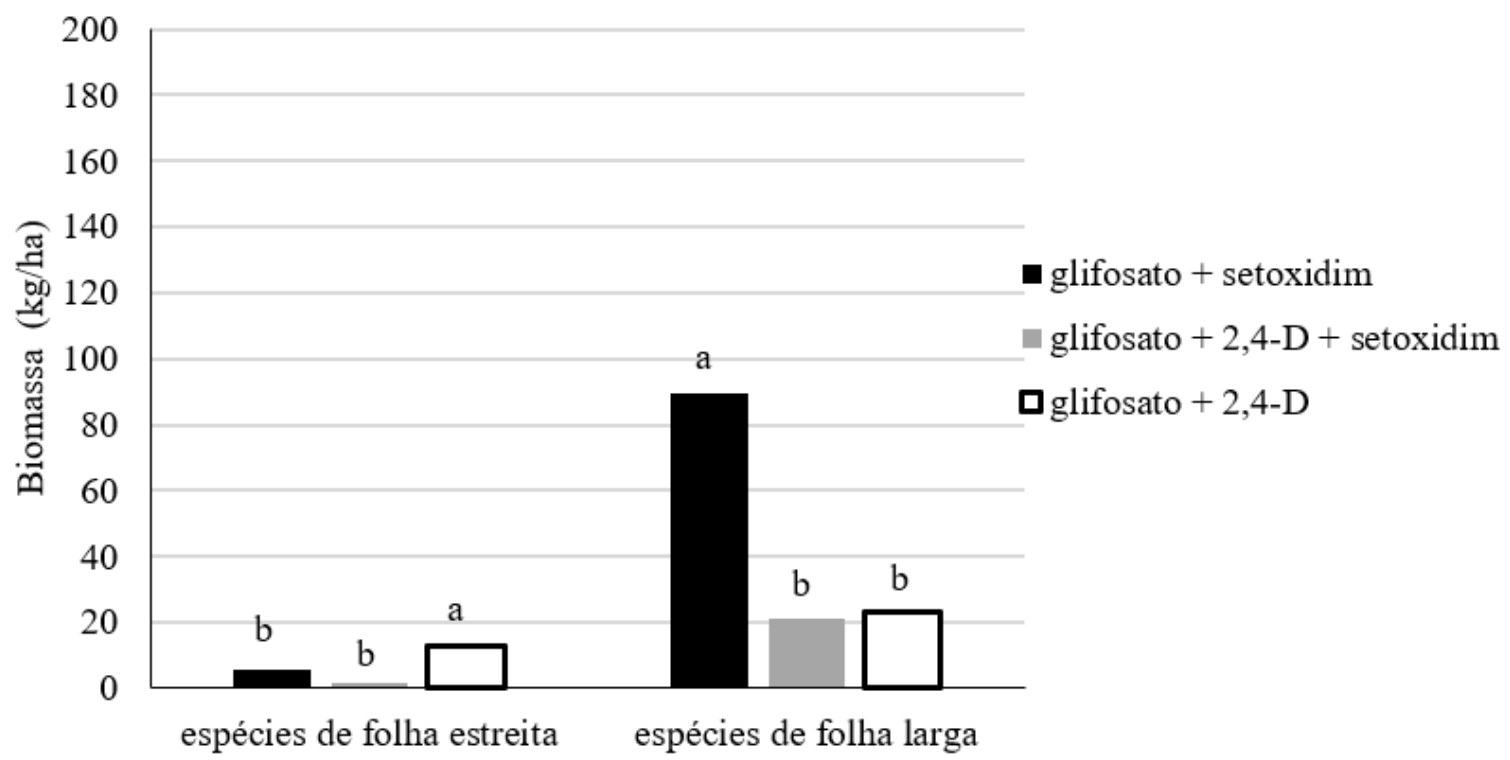

Figura 4. Biomassa de plantas daninhas aos 75 dias após dessecação pré-semeadura da soja (35 dias após a semeadura da soja), utilizando diferentes associações herbicidas. Médias seguidas pela mesma letra dentro de cada grupo de plantas não diferem entre si pelo teste de Tukey a $5 \%$ de probabilidade de erro. CV espécies folha estreita $=31 \%$. CV espécies de folha larga $=28 \%$.

Tabela 2. Índice de Clorofila Falker (ICF) da cultura da soja em estádio fenológico R 5.2, submetida à diferentes tratamentos herbicidas em dessecação pré-semeadura.

\begin{tabular}{cc}
\hline Tratamentos & ICF \\
\hline glifosato + setoxidim & 54,49 \\
glifosato $+2,4-\mathrm{D}+$ setoxidim & 54,88 \\
glifosato $+2,4-\mathrm{D}$ & 55,22 \\
\hline $\mathrm{F}$ & $0,33^{\mathrm{NS}}$ \\
$\mathrm{CV} \%$ & 3,28 \\
\hline
\end{tabular}

${ }^{\mathrm{NS}}$ Não significativo pelo teste F.

Tabela 3. Médias de altura do primeiro nó, altura de planta, número de nós no caule, número de vagens por planta, número de grãos por vagem, peso de mil grãos e rendimento de grãos de soja submetida a diferentes associações herbicidas na dessecação pré-semeadura.

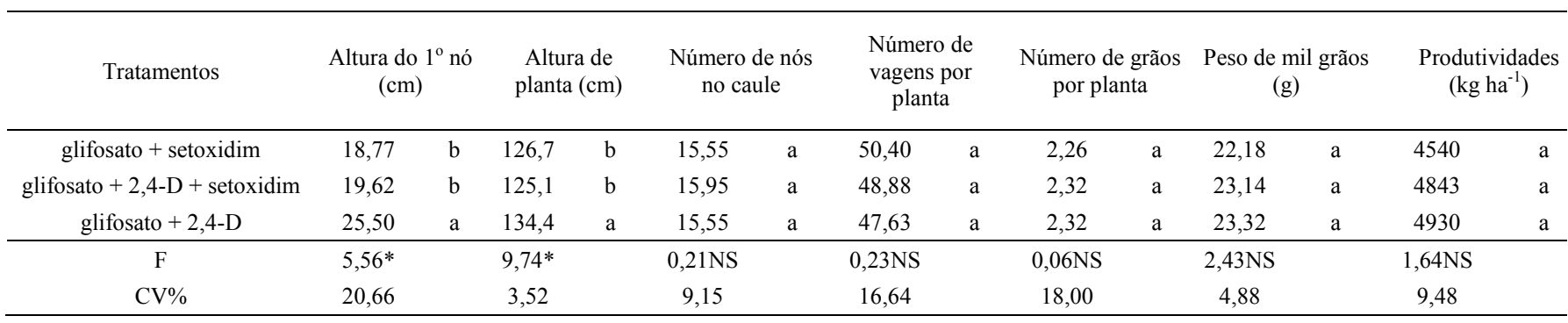

${ }^{1}$ Médias seguidas pela mesma letra minúscula na coluna não diferem entre si pelo teste de Tukey a $5 \%$ de probabilidade de erro. * significativo a $5 \%$ de probabilidade pelo teste $\mathrm{F}^{\text {. NS }}$ Não significativo pelo teste $\mathrm{F}$.

As associações do herbicida glifosato com setoxidim e 2,4-D proporcionaram controle superior das plantas daninhas resistentes ao glifosato (Figuras 2, 3 e 4). Tal resultado é esperado, uma vez que a utilização de múltiplos mecanismos de ação é uma ferramenta importante para reduzir e manejar a evolução de plantas daninhas resistentes
(VENCILL
et al.,
2012;
BRUNHARO;

CHRISTOFFOLETI; NICOLAI, 2014). Para combater a 
rápida seleção e dispersão da resistência da buva, planta daninha resistente ao glifosato com maior distribuição mundial, muitos autores demonstram a importância da combinação do glifosato com outro herbicida (HEAP, 2014; DALAZEN et al., 2015b).

No presente estudo, as espécies de folha larga, compostas principalmente por buva resistente ao glifosato, apresentaram um grande aumento na biomassa, após 20 dias da aplicação do dessecante sem a associação com o latifolicida 2,4-D. Em todas as avaliações de biomassa das plantas daninhas (Figuras 2, 3 e 4), a combinação glifosato + 2,4-D na dessecação antecipada em pré-semeadura proporcionou um controle significativo das plantas daninhas de folha larga (máximo de $78 \mathrm{~kg} \mathrm{ha}^{-1}$ ) quando comparado ao glifosato + setoxidim (197 kg ha ${ }^{-1}$ ) (Figura 3). A associação do glifosato +2 ,4-D é uma prática já consolidada na produção de grãos, sendo reportada também por outros trabalhos, como o de Takano et al. (2013). Vale ressaltar que outros herbicidas também podem ser importantes para o manejo de buva resistente ao glifosato, como é o caso do saflufenacil, de mecanismo de ação inibidor de protoporfirinogênio oxidase (PROTOX), que se mostrou eficaz em estudos de Owen et al. (2011) e Dalazen et al. (2015b).

A associação de glifosato com graminicidas é importante também para o manejo de resistência à herbicidas inibidores da acetolactato sintase (ALS). No Rio Grande do Sul, Mariani et al. (2016) relataram que glifosato e o cletodim, do mesmo grupo químico do setoxidim (ciclohexanodiona), além de outros herbicidas de ação préemergente, mostraram-se como uma ferramenta útil para o manejo de resistência ao inibidor de ALS iodosulfurommetílico sódio.

O aumento expressivo da biomassa de plantas daninhas de folha larga dos 20 aos 35 dias após a aplicação dos tratamentos herbicidas pode ser explicado pelo crescimento e desenvolvimento de plantas daninhas que germinaram e se desenvolveram em seguida e, principalmente, pelo rebrote de buva que sofreram aplicação herbicida em estágio de desenvolvimento mais avançado. É sabido que o estádio de crescimento das plantas de buva, resistente ou não ao glifosato, influencia sobremaneira a eficácia do controle químico (VARGAS; GAZZIERO, 2009; BRESSANIN et al., 2014).

As plantas daninhas, de forma geral, apresentaram redução de biomassa na última avaliação, aos 75 dias após a dessecação pré-semeadura (Figura 4). Essa redução pode ser decorrente da presença do azevém, cuja senescência coincide com o fechamento e sombreamento da cultura de verão. Esta gramínea é anual, desenvolve-se no outono, inverno e início da primavera, competindo, tradicionalmente, com a cultura do trigo pelos recursos do meio (MARIANI et al., 2016). No entanto, lavouras de soja implantadas no início do período do zoneamento estabelecido para cultura, podem apresentar redução na produtividade em altas infestações.

Com relação às espécies de folha larga, a buva foi manejada durante o seu desenvolvimento inicial, em pré- semeadura, sendo desfavorecida quando em competição com a cultura da soja, após o estabelecimento da cultura. Já espécies de folha larga de inverno, como a nabiça (Raphanus raphanistrum L.) tiveram seu ciclo fechado no início do verão. Portanto, aos 75 dias após a dessecação, que coincidiu com 35 dias após a semeadura da soja, as plantas de folha larga estavam presentes de forma limitada em número e biomassa, o que pode explicar o resultado de a produtividade da soja não diferir entre os tratamentos testados.

Para os alvos, especialmente buva e azevém, não foram encontrados efeitos de sinergismo ou antagonismo nas associações dos herbicidas glifosato, 2,4-D e setoxidim, mas apenas efeito de adição. Esse resultado difere do encontrado por Flint e Barret (1989), que obtiveram antagonismo entre 2,4-D, além do dicamba, e glifosato para o controle de Sorghum halepense (L.), em que os mimetizadores de auxina prejudicaram a absorção e a translocação do inibidor de EPSPs. Dalazen et al. (2015b) relataram efeito sinérgico e prevenção da ocorrência de rebrote e dispersão de novas sementes de buva com a associação de glifosato com saflufenacil, de forma superar a aplicação de saflufenacil isolado. As associações desses herbicidas, entretanto, não proporcionaram efeito de sinergismo ou antagonismo em Brachiaria decumbens Stapf., em estudos de Queiroz et al. (2014), no interior do estado de São Paulo.

Com relação ao setoxidim, associações já foram estudadas com os herbicidas bentazona, acifluorfem e clorimurom, em doses baixas, não proporcionando controle satisfatório de plantas daninhas de folha larga na cultura da soja (STECKEL; DEFELICE; SIMS, 1990). Já Minton, Kurtz e Shaw (1989) identificaram que o setoxidim sofreu antagonismo também quando combinado com imazaquim. Quando combinado com acifluorfem, setoxidim incrementou o controle de Echinochloa crus-galli (L.) Beauv., em estudos de Chen e Penner (1985).

A altura do primeiro nó visível e a altura das plantas de soja foram maiores no tratamento com glifosato + 2,4-D. A presença de biomassa no momento da aplicação dos tratamentos experimentais foi muito maior em plantas daninhas de folha estreita no início do ciclo da cultura (Figura 1). Nos tratamentos sem a aplicação do graminicida setoxidim as plantas de folha estreita mantiveram o crescimento vegetativo por maior período, elevando a quantidade de biomassa na superfície do solo, consequentemente induzindo um maior alongamento dos primeiros nós.

Os diferentes tratamentos de dessecação présemeadura não proporcionaram efeito no índice de clorofila, no rendimento e nos componentes de rendimento de grãos da cultura da soja. Isso demonstra que as plantas daninhas resistentes ao glifosato presentes nos tratamentos sem a utilização de herbicidas recomendados pela bula, apesar de presentes em biomassa significativamente maior em todas as avaliações, não foram suficientes para interferir no crescimento, desenvolvimento e rendimento da cultura da soja 'TMG 7062 IPRO'. 


\section{Conclusões}

Não foram encontrados efeitos de sinergismo ou antagonismo para o controle de buva e azevém pelas associações dos herbicidas glifosato, 2,4-D e setoxidim, apenas efeito de adição.

Nas condições de infestação de daninhas do experimento, os componentes de rendimento e a produtividade da cultura da soja não diferiram com associações de glifosato com 2,4-D e/ou setoxidim na dessecação pré-semeadura da cultura.

\section{Referências}

Agrofit (2019) Ministério da Agricultura, Pecuária e Abastecimento. Consulta de produtos formulados, 2019. 6 Disponível em: <http://agrofit.agricultura.gov.br/ agrofit_cons/principal_agrofit_cons $>$ Acesso em: 27 jan. 2019.

Amim, R. T.; Freitas, S. P.; Freitas, I. L. J.; Gravina, G. A.; Paes, H. M. F. Controle de plantas daninhas pelo indaziflam em solos com diferentes características físico-químicas. Planta daninha, v. 32, n. 4, p. 791-800, 2014.

Barros, J.; Calado, J. Rotação de herbicidas em trigo para prevenir a resistência das infestantes em condições Mediterrânicas. Revista de Ciências Agrárias, v. 43, n. 1, p. 3-13, 2020 .

Bhatti, K. H.; Parveen, T.; Farooq, K. N.; Hussain, K.; Siddiqui, E. H. A Critical Review on Herbicide Resistance in Plants. World Applied Sciences Journal, v. 27, n. 8, p. 1027-1036, 2013

Bressanin, F. N. Jayme Neto, N.; Martins, J. F.; Martins, J. V. F.; Alves, P. L. C. A. Controle de biótipos resistentes de Conyza bonariensis com glyphosate + clorimuron-etílico em função do estádio de desenvolvimento. Revista Brasileira de Herbicidas, v. 13, n. 1, p. 68-72, 2014.

Brunharo, C. A. C. G.; Christoffoleti, P. J.; Nicolai, M. Aspectos do mecanismo de ação do amônio glufosinato: culturas resistentes e resistência de plantas daninhas. Revista Brasileira de Herbicidas, v. 13, n. 2, p. 163-177, 2014.

Chen, Y. Z.; Penner, D. Combination effects of acifluorfen with crop oil concentrates and postemergence grass herbicides. Weed Science, v. 33, n. 1, p. 91-95, 1985.

Costa, L. L. et al. Interação entre herbicidas no controle de soja RR voluntária na cultura do milho. Revista Brasileira de Herbicidas, v. 18, n. 2, p. 1-8, 2019.

CQFS-RS/SC - Comissão de Química e Fertilidade do Solo - RS/SC. Manual de adubação e calagem para os Estados do Rio Grande do Sul e Santa Catarina. Santa Maria:
Núcleo Regional Sul - Sociedade Brasileira de Ciência do Solo. 2016. 376 p.

Dalazen, G.; Kruse, N. D.; Machado, S. L. O. Herbicidas de uso potencial no controle de buva e sua seletividade sobre aveia e azevém. Revista Ciência Agronômica, v. 46, n. 4, p. 792-799, 2015a.

Dalazen, G.; Kruse, N. D.; Machado, S. L. O.; Balbinot, A. Sinergismo na combinação de glifosato e saflufenacil para o controle de buva. Pesquisa Agropecuária Tropical, v. 45, n. 2, p. 249-256, 2015 b.

Embrapa - Empresa Brasileira de Pesquisa Agropecuária. 2018. Dados Econômicos da safra 2017/2018. Online. Disponível em: <https://www.embrapa.br/web/portal/soja/ cultivos/soja1/dados-economicos $>$. Acesso em: 24 fev. 2019.

Ferreira, D. F. Sisvar: a computer statistical analysis system. Ciência e Agrotecnologia, v. 35, n. 6, p. 1039-1042, 2011.

Flint, J.; Barrett, M. Antagonism of glyphosate toxicity to johnsongrass (Sorghum halepense) by 2,4-D and dicamba. Weed Science, v. 37, n. 5, p. 700-705, 1989.

Heap, I. Global perspective of herbicide-resistant weeds. Pest Management Science, Oxford, v. 70, n. 9, p. 1306$1315,2014$.

Köppen, W. Climatologia: con un studio de los climas de la tierra. México: Fondo de Cultura Economica, 1948. 478 p.

Lorenzi, H. Manual de Identificação e Controle de Plantas Daninhas: Plantio direto e convencional. $6^{\text {a }}$ Edição. São Paulo: Instituto Plantarum de Estudos da Flora Ltda. 2006, 339 p.

Mariani, F.; Vargas, L.; Agostinetto, D.; Fraga, D. S.; Santos, F. M.; Piesanti, S. R. Resistência de biótipos de azevém ao herbicida iodosulfurom-metílico sódio e herbicidas alternativos para o controle. Revista de la Facultad de Agronomía, v. 115, n. 1, p. 35-43, 2016.

Minton, B. W.; Kurtz, M. E.; Shaw, D. R. Barnyard grass (Echinochloa cruz-galli) control with grass and broadleaf weed herbicide combinations. Weed science, v. 37, n. 2, p. 223-227, 1989.

Owen, L. N.; Mueller, T. C.; Main, C. L.; Bond, J.; Steckel, L. E. Evaluating rates and application timings of saflufenacil for control of glyphosate-resistant horseweed (Conyza canadensis) prior to planting no-till cotton. Weed Technology, v. 25, n. 1, p. 1-5, 2011.

Queiroz, J. R. G.; Junior, A. C. S.; Costa, A. C. P. R.; Martins, D. Eficiência da aplicação da mistura de glyphosate com saflufenacil sobre plantas de Brachiaria decumbens. Revista Brasileira de Herbicidas, v. 13, n. 1, p. 1-7, 2014. 
Rodrigues, B. N.; Almeida, F. S. Guia de herbicidas. $6^{\mathrm{a}}$ ed., Londrina, 2011. 697 p.

Santos, H. G. et al. Sistema brasileiro de classificação de solos. 5.ed. rev. e ampl. Brasília: Embrapa, 2018. 586 p.

Sediyama, T.; Silva, F.; Borém, A. (2015). Soja: do plantio a colheita. Viçosa, MG: UFV. 333 p.

Steckel, L. E., Defelice, M. S.; Sims, B. D. Integrating reduced rates of postemergence herbicides and cultivation for broadleaf weed control in soybeans (Glycine max). Weed Science, v. 38, n. 6, p. 541-545, 1990.

Takano et al. Efeito da adição do 2,4-D ao glyphosate para o controle de espécies de plantas daninhas de difícil controle. Revista Brasileira de Herbicidas, v. 12, n. 1, p. 1-13, 2013.

Vargas, L.; Gazziero, D. L. P. 2009. Manejo de buva resistente ao glyphosate. Passo Fundo: Embrapa Trigo. 14 p. (Documentos, 91).

Vencill, W. K.; Nichols, R. L.; Webster, T. M.; Soteres, J. K.; Mallory-Smith, C.; Burgos, N. R. Johnson, W. G.; Mcclelland, M. R. Herbicide resistance: toward an understanding of resistance development and the impact of herbicide resistant crops. Weed Science, v. 60, p. 2-30, 2012 .

Zavariz, A.; Berryhill, Q. T. A.; Guimarães, E. T.; Pereira, F. A. C. A utilização de glifosato no cultivo de café, um estudo epistemiológico. Brazilian Journal of Development, v. 6, n. 6, p. 36046-36058, 2020. 